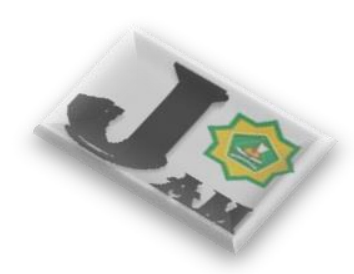

Al-Muqayyad

ISSN (print): 2715-3177 | ISSN (online): 2614-8102

Program Studi Ekonomi Syariah, STAI Auliaurrasyidin Tembilahan

Journal Homepage: https://ejournal.stai-tbh.ac.id/index.php/al-muqayyad

\title{
Pengaruh Sistem Informasi Penerimaan Pajak Reklame terhadap Peningkatan Pendapatan Asli Daerah Kabupaten Bengkalis
}

\author{
*Irawan Fakhrudin Mahalizikri 1, a, Nurfaizana Arnabilla ${ }^{2, b}$ \\ 1) Sekolah Tinggi Ilmu Ekonomi Syariah Bengkalis, Indonesia \\ ${ }^{2)}$ Sekolah Tinggi Ilmu Ekonomi Syariah Bengkalis, Indonesia \\ Email: airawanfma@gmail.com; ㅎnurfa.zanaa@ymail.com
}

DOI:

https://doi.org/10.469

63/jam.v4i2.388

Cara Mensitasi Artikel ini:

Mahalizikri, I. F, \& Arnabilla, N. (2021). Pengaruh sistem informasi penerimaan pajak reklame terhadap peningkatan pendapatan asli daerah Kabupaten Bengkalis, 4(2), 84-97. https://doi.org/10.46963/jam.v4i2.388

\section{Keywords:}

Advertising Tax, Receipt Information

System, Local

Revenue

\section{Kata Kunci:}

Pajak Reklame,

Sistem Informasi

Penerimaan,

Pendapatan Asli

Daerah

\section{Informasi Artikel:}

Diterima:

$12 / 08 / 2021$

Direvisi:

Diterbitkan

$30 / 12 / 2021$

\section{*Corresponding}

Author

irawanfma@gmail.co

$\underline{\mathrm{m}}$

\section{ABSTRACT}

This article aims to determine the effect of the advertisement tax revenue information system on increasing the local revenue of Bengkalis Regency. The information system applied is still using the advertisement information system manually. Where the manual information system is applied: the first is the information system for the management and calculation of the advertisement tax, the second is the information system for the appeal of the taxpayer and the organizer of the advertisement tax through electronic media and the third banner is the information system for the recapitulation of targets and realization of the advertisement tax using the standard application of Microsoft Excel. The researcher used the collection techniques: interviews, documentation, questionnaires, and literature studies. The data analysis technique used: respondent's data test, data quality test, classical assumption test, hypothesis test and simple linear regression test, while the results studied were known in the t-test (partial) that the value of tcount 8.168> ttable 1.983. Meanwhile, based on the significant value of the t-test (partial) it can be seen in the sig table column that the significant value is $0.000<0.05$. So it can be concluded that there is an influence between the Advertising Tax Revenue Information System variable $(X)$ on the Regional Original Income Increase variable $(Y)$ by $39.3 \%$, the rest is influenced by other variables of $60.7 \%$.

\section{ABSTRAK}

Artikel ini bertujuan mengetahui pengaruh sistem infromasi penerimaan pajak reklame terhadap peningkatan pendapatan asli daerah Kabupaten Bengkalis. Sistem informasi yang diterapkan masih menggunakan sistem informasi reklame secara manual. Dimana sistem informasi manual yang diterapkan: pertama sistem informasi pengelolaan dan perhitungan pajak reklame, kedua sistem informasi himbauan wajib pajak dan penyelenggara pajak reklame melalui media elektronik dan sepanduk ketiga sistem infromasi rekapitulasi target dan relisasi pajak reklame menggunakan aplikasi standar microsoft excel. Peneliti menggunakan teknik pengumpulan: wawancara, dokumentasi, kuesioner, dan studi pustaka. Teknik analisis data menggunakan: uji data responden, uji kualitas data, uji asumsi klasik, uji hipotesis dan uji regresi linear sederhana, adapun hasil yang diteliti diketahuidalam uji $t$ (Parsial)bahwa nilai thitung8,168> ttabel1,983. Sedangkan berdasarkan nilai signifikanuji $t$ (Parsial) dapat dilihat pada kolom tabel sig bahwa nilai signifikansebesar 0,000 $<0,05$. Sehingga disimpulkan bahwa adanya pengaruh antara variabel Sistem Informasi Penerimaan Pajak Reklame (X) terhadap variabel Peningkatan Pendapatan Asli Daerah (Y) sebesar 39,3\% sisanya dipengeruhioleh variabel lain sebesar 60,7\%. 
Pengaruh Sistem Informasi Penerimaan Pajak Reklame terhadap Peningkatan ........

\section{PENDAHULUAN}

Dalam praktik di masyarakat, pungutan pajak daerah sering kali disamakan dengan retribusi daerah. Hal ini didasarkan pada pemikiran bahwa keduanya merupakan pembayaran kepada pemerintah. Pandangan init tidak sepenuhnya benar karena pada dasarnya terdapat perbedaan yang besar antara pajak dan retribusi. Oleh sebab itu, sebelum membahas pajak daerah dan retribusi daerah yang di pungut di Indonesia, perlu kiranya diketahui pengertian kedua jenis pungutan ini secara lebih jelas lagi. (Marihot Pahala Siahaan, 2003).

Dewasa ini, pajak daerah terdiri dari berbagai jenis pajak yang terkait dengan berbagai sendi kehidupan masyarakat. Demikiran pula dengan restribusi daerah. Masing-masing jenis pajak dan restribusi daerah memiliki objek, subjek, tarif, dan berbagai ketentuan pengenaan tersendiri, yang mungkin berbeda dengan jenis pajak atau retribusi daerah lainnya. Di sisi lain, semangat otonomi daerah yang diberlakukan di Indonesia memungkinkan setiap daerah provinsi atau kabupaten/kota mengatur daerahnya sendiri, termasuk dalam bidang pajak dan retribusi daerah. Segala kondisi di atas memang din mungkinkan dalam pengenaan dan pemungutan pajak dan retribusi daerah. Agar tidak membingungkan dan merugikan masyarakat, peraturan tentang pajak dan retribusi daerah harus disosialisasikan kepada masyarakat sehingga dapat dipahami dengan jelas. (Marihot Pahala Siahaan, 2003).

Secara umum pajak adalah pungutan dari masyarakat oleh negara (pemerintah) berdasarkan undang-undang yang bersifat dapat di paksakan dan terutang oleh yang wajib membayarnya dengan tidak mendapat prestasi kembali (kontra prestasi/balas jasa) secar langsung, yang hasil digunakan untuk membiayai pengeluaran negara dalam penyelenggaraan pemerintahan dan pembangunan. Hal ini menunjukkan bahwa pajak adalah pembayaran wajib yang dikenakan berdasarkan Undang-Undang yang tidak dapat di hindari bagi ynag berkewajiban dan bagi mereka yang tidak mau membayar pajak dapat dilakukan paksaan. Jadi, sistem informasi merupakan usaha untuk membangun sistem berdasarkan komputer (Computer Based Information System/CBIS) yang digunakan untuk memberikan informasi pemecahan masalah kepada pengguna. Sistem informasi dapat juga di artikan sebagai sebagai suatu sistem berdasarkan komputer yang menjadikan informasi dapat di gunakan oleh para manajer untuk kebutuhan yang sama. Informasi yang dihasilkan dapat disajikan dalam bentuk laporan berkala, laporan khusus, dan laporan dalam bentuk simulasi matematis. Informasi perpajakan adalah dokumen dan atau data perpajakan dalam bentuk digital yang terdapat dalam aplikasi Sistem Informasi Perpajakan di Direktorat Jenderal Pajak termasuk pada unit organisasi vertikalnya. Menurut peraturan direktur jenderal pajak nomor: per-160/PJ/2006, Sistem Informasi Perpajakan (SIP) adalah sistem informasi dalam administrasi perpajakan di lingkungan Kantor Direktorat Jenderal Pajak dengan menggunakan perangkat keras dan perangkat lunak yang dihubungkan dalam suatu jaringan kerja lokal. (Eka Lestari, 2008:7)

\section{Al-Muqayyad}

Vol 4 No 2 (2021) 
Pajak reklame merupakan pajak yang dipungut atas semua penyelengaraan reklame baik oleh orang pribadi maupun semua penyelenggaraan badan. Alasan kenapa mengambil pajak reklame ialah dikarenakan pajak reklame di Kabupaten Bengkalis cukup potensial, serta reklame mudah ditemui disetiap ruas jalan yang ada di kabupaten Bengkalis. Pemerintah Kabupaten Bengkalis melihat hal tersebut merupakan potensi yang dapat dipergunakan bagi pembangunan daerah Bengkalis dengan mengeluarkan Perda No. 11 Tahun 2011 tentang Pajak Daerah dengan tujuan untuk dapat memberikan penerimaan bagi PAD Kabupaten Bengkalis sehingga diberikan target-target pada setiap tahunnya, tugas dan kewenangan pengimplementasiannya diserahkan kepada Dinas Pendapatan Daerah Kabupaten Bengkalis.

Selain pajak reklame, dalam pendapatan asli daerah juga terdapat pajak restoran yaitu pajak restoran, pajak restoran ini dikenakan kepada wajib pajak, yang mempunyai restoran baik besar maupun kecil yang berada di daerah sekitar Kabupaten Bengkalis. Sesuai dengan undang-undang pajak dan retribusi daerah, (UU pajak daerah dan retribusi daerah yang baru undang- undang No 28 Tahun 2009), salah satu jenis pajak Kabupaten/Kota adalah pajak restoran. Sesuai ketentuan pasal 40 undang-undang baru, besar tarif pajak restoran ditetapkan paling tinggi $10 \%$ dari omset penjualan. Besarnya pajak restoran ditetapkan oleh masing-masing pemerintah daerah Kabupaten/Kota, sehingga mungkin akan terdapat perbedaan tarif pajak restoran didaerah satu dengan yang lainnya.

Berdasarkan hasil penelitian dan dari kondisi yang objektif yang peneliti lakukan di Badan Pendapatan Daerah Kabupaten Bengkalis, untuk melihat relisasi pajak reklame yang belum tercapai targetnya dari tahun ke tahun. Adapun relisasi pajak reklame pada Badan Pendapatan Daerah Kabupaten Bengkalis. Sebagai berikut:

Tabel 1.1

Penerimaan Pajak Reklame

\begin{tabular}{cccccc}
\hline No & Tahun Anggaran & Jenis pajak & Target & Relisasi & Persentase \\
\hline 1 & 2015 & Reklame & $279.000 .000,00$ & $327.602 .463,00$ & $117,42 \%$ \\
2 & 2016 & Reklame & $300.000 .000,00$ & $332.298 .163,00$ & $110,77 \%$ \\
3 & 2017 & Reklame & $500.000 .000,00$ & $318.824 .101,00$ & $63,76 \%$ \\
\hline
\end{tabular}

Sumber: Arsip Bidang Pembukuan dan Verifikasi BAPENDA Kabupaten Bengkalis

Berdasarkan tabel diatas pada tahun 2015-2016 realisasi tercapai dikarena faktor banyaknya penyelenggara reklame yang patuh dalam membayar pajak reklame pada Badan Pendapatan Daerah Kabupaten Bengkalis. Sedangkan pada tahun 2017, realisasi pajak reklame belum tercapainya dikarenakan faktor kurang minatnya penyelenggara reklame pada saat tahun 2017. Berdasarkan indikator diatas, Maka masalah yang dapat penulis disimpulkan disebabkan sebagai berikut:

1. Belum tersosialisasikan sistem informasi penerimaan pajak reklame pada daerah

2. Kabupaten Bengkalis. 
Pengaruh Sistem Informasi Penerimaan Pajak Reklame terhadap Peningkatan ........

3. Penerimaan pajak reklame yang belum tercapai relisasinya dari tahun ke tahun.

4. Pendapatan asli daerah yang belum optimal dari sektor pajak reklame dan sumber

5. daya manusia.

Pendapatan Asli Daerah (PAD) merupakan salah satu modal dasar Pemerintah Daerah dalam mendapatkan dana pembangunan dan memenuhi belanja daerah. Pendapatan Asli Daerah merupakan suatu usaha guna memperkecil ketergantungan dalam mendapatkan dana dari pemerintah tingkat atas (Subsidi). Pada dasarnya Pendapatan Asli Daerah seyogyanya ditunjang oleh hasil-hasil perusahaan daerah, perusahaan pasar, Pajak Reklame, Pajak Retribusi Kendaraan dan Kebersihan, pajak Bumi dan Bangunan serta usaha sah lainnya. Sumber pendapatan daerah yang potensial diserahkan kepada daerah otonomi tersebut.

Dalam penelitian Khuzain Rahman "Pengaruh Pemungutan Pajak Reklame Terhadap Pendapatan Asli Daerah (PAD) Ditinjau Dalam Perspektif Ekonomi Islam (Studi Kasus Di Kota Bandar Lampung Tahun 2010-2015)" Berdasarkan hasil penelitian menunjukan bahwa pajak reklame berpengaruh terhadap PAD kota Bandar Lampung, Variabel pajak reklame dengan t hitung sebesar 13,431 lebih besar dari t tabel yaitu sebesar 2,77645 $\mathrm{t}$ hit $>\mathrm{t}$ tabel atau nilai signifikan lebih kecil dari alpha 0,05 yaitu $0,000(0,000>0,05)$. Dalam ekonomi Islam pemungutan pajak khususnya pajak reklame di kota Bandar Lampung telah sesuai dengan prinsip keadilan dan selalu dalam pengawasan yang bertujuan untuk mewujudkan maqashid syari'ah. Berkaitan dengan penelitian ini disarankan kepada pemerintah Mekanisme dan cara kerja aparatur pelaksanaan pengawasan pajak daerah perlu diperhatikan, khususnya memiliki fungsi untuk memperlancar dan mensukseskan pemungutan pajak terutama pajak reklame yang menjadi fokus penelitian agar mencapai target rekalme yang semakin tinggi sehingga mampu memberikan kontribusi yang lebih tinggi terhadap Pendapatan Asli Daerah di Kota Bandar Lampung, mengadakan pendataan dan pengawasan secara rutin agar meminimalisir adanya masalah reklame liar yang tidak terdapat dilapangan, dan perlu menjaga komunikasi dengan wajib pajak dan sosialisasi dengan wajib pajak yang lebih intensif, sehingga wajib pajak merasa di perhatikan oleh pemerintah sebagai mitra dan patuh membayar pajak.

Dalam penelitian lainnya Menurut Della Nurnaafiyanti "Pengaruh Penerimaan Pajak Reklame Terhadap Penerimaan Pendapatan Asli Darah (PAD) Kota Cimahi (Studi Kasus Pada Dinas Pendapatan Asli Daerah Kota Cimahi) Penelitian ini bertujuan untuk mengetahui pengaruh penerimaan pajak reklame terhadap pendapatan asli daerah (PAD) kota Cimahi. Variabel independen yang digunakan dalam penelitian ini adalah penerimaan pajak reklame, sedangkan variabel dependen dalam penelitian ini adalah pendapatan asli daerah (PAD). Sampel penelitian ini adalah realisasi

pendapatan daerah kota Cimahi selama 5 tahun yaitu dari tahun 2010 sampai dengan 2014. Sampel penelitian dipilih dengan metode purposive sampling. Metode 
penelitian yang digunakan dalam penelitian ini adalah metode explanatory dengan melakukan penelitian lapangan dan pendekatan kepustakaan. Analisis dalam penelitian ini menggunakan analisis regresi linier sederhana. Hasil penelitian menunjukkan bahwa penerimaan pajak reklame berpengaruh signifikan terhadap PAD dengan tingkat signifikansi sebesar 5\%. Nilai koefisien determinasi sebesar 95,06\%. Hasil uji hipotesis didapat nilai thitung $=7,603534>$ ttabel $=2,35336$, maka Ho ditolak dan Ha diterima.

\section{METODE}

Populasi dari penelitian ini adalah seluruh karyawan/pegawai pada Badan Pendapatan Daerah (BAPENDA) Kabupaten Bengkalis 142 populasi.Dalam penelitian digunakan adalah teknik simple random sampling.Jumlah sampel ditentukan dengan rumus slovin. (Muri Yusuf A, 2014:170-1210)

$$
\mathrm{n}=\frac{\mathrm{N}}{1+\left(\mathrm{N} \mathrm{x} \mathrm{e}^{2}\right)}
$$

Keterangan :

$\mathrm{n}=$ Jumlah elemen/anggota sampel

$\mathrm{N}=$ Jumlah elemen/anggota populasi

e $\quad=$ Error level (tingkat kesalahan) (catatan: umumnya digunakan 1\%, 0,01, atau $5 \%, 0,05$, dan $10 \%$ atau 0,1 (catatan dapat dipilih oleh peneliti). Jumlah elemen populasi $(\mathrm{N})=142$ orang, error level yang ditetapkan oleh peneliti 5\%, maka jumlah sampelnya:

$$
\begin{aligned}
\mathrm{n} & =\frac{142}{1+(142 \times 0,05)} \\
& =104,79=105 \text { orang }
\end{aligned}
$$

Jumlah sampel pihak pegawai dan honorer serta petugas lapangan pada Badan Pendapatan Daerah Kabupaten Bengkalis yaitu sebanyak 105 orang.

Dalam penelitian ini data yang diperoleh wawancara,kuesioner,dokumentasi dan studi kepustakaan.Adapun teknik analisis data yang digunakan dalam penelitian ini uji data responden,uji kualitas data,uji asumsi klasik, uji analisis korelasi pearson,uji hipotesis,uji regresi linier sederhana, dan uji koefisien determinasi. 
Pengaruh Sistem Informasi Penerimaan Pajak Reklame terhadap Peningkatan

\section{HASIL DAN PEMBAHASAN}

Berikut rekapitulasi Adapun hasil penerimaan pajak reklame dan penerimaan pendapatan asli daerah pada Badan Pendapatan Daerah Kabupaten Bengkalis dari tahun 2015-2018 sebagai berikut:

Tabel 3.1

Relisasi Penerimaan Pajak Reklame

Tahun 2015-2018

\begin{tabular}{ccccc}
\hline Tahun & Jenis Pajak & Target & Relisasi & Persentase \\
\hline 2015 & Pajak Reklame & 279.000 .000 & 327.602 .463 & $117,42 \%$ \\
2016 & Pajak Reklame & 300.000 .000 & 332.298 .163 & $110,77 \%$ \\
2017 & Pajak Reklame & 500.000 .000 & 318.824 .101 & $63,76 \%$ \\
2018 & Pajak Reklame & 2.100 .000 .000 & 459.846 .236 & $21,90 \%$
\end{tabular}

Sumber: Data Laporan Penerimaan Pada BAPENDA Kabupaten Bengkalis

Sedangkan relisasi penerimaan pendapatan asli daerah Kabupaten Bengkalis dapat dilihat pada tabel sebagai berikut:

Tabel 3.2

Relisasi Penerimaan Pendapatan Asli Daerah Tahun 2015-2018

\begin{tabular}{cccc}
\hline Tahun & Target & Relisasi & Persentase \\
\hline 2015 & $337.287 .017 .893,16$ & $257.943 .710 .718,18$ & $76,48 \%$ \\
2016 & $335.584 .167 .284,53$ & $199.008 .268 .547,10$ & $59,30 \%$ \\
2017 & $373.540 .392 .000,00$ & $143.976 .405 .848,08$ & $38,54 \%$ \\
2018 & $445.510 .450 .102,00$ & $300.628 .186 .822,38$ & $67,63 \%$
\end{tabular}

Sumber: Data Laporan Penerimaan Pada BAPENDA Kabupaten Bengkalis Data Responden

Berdasarkan kuesioner yang disebarkan kepada responden,maka diperoleh data yang berkenaan dengan responden yang menjadi sampel dalam hal penelitian mencakup hal-hal mengenai jenis kelamin dan umur yang menjadi responden dalam penelitian ini.Kuesioner yang disebar sebanyak 105 Orang.Setelah dilakukan karakteristik responden dalam penelitian ini terbagi dalam beberapa kategori,yaitu Gender (jenis kelamin) dan umur. (Husaini Usaman dan Purnomo Stiady Akbar, 2011:3-4)

Al-Muqayyad

Vol 4 No 2 (2021) 
Irawan fakhrudin Mahalizikri, \& Nurfaizana Arnabilla

Tabel 3.3

Distribusi Responden berdasarkan jenis kelamin

Jenis Kelamin

\begin{tabular}{llcccc}
\hline & & & $\begin{array}{c}\text { Valid } \\
\text { Percent }\end{array}$ & $\begin{array}{c}\text { Cumulative } \\
\text { Percent }\end{array}$ \\
\hline Valid & Laki-Laki & 58 & 55.2 & 55.2 & 55.2 \\
& Perempuan & 47 & 44.8 & 44.8 & 100.0 \\
& Total & 105 & 100.0 & 100.0 & \\
\hline
\end{tabular}

Sumber :Data olahan

Tabel IV 3.4

Distribusi Responden berdasarkan Umur

\begin{tabular}{|c|c|c|c|c|c|}
\hline \multicolumn{6}{|c|}{ Umur } \\
\hline & & Frequency & $y$ Percent & $\begin{array}{l}\text { Valid } \\
\text { Percent }\end{array}$ & $\begin{array}{l}\text { Cumulative } \\
\text { Percent }\end{array}$ \\
\hline \multirow[t]{4}{*}{ Valid } & $25-30$ & & 2321.9 & 21.9 & 21.9 \\
\hline & $31-40$ & & 4139.0 & 39.0 & 61.0 \\
\hline & $>41$ & & 4139.0 & 39.0 & 100.0 \\
\hline & Total & 105 & 100.0 & 100.0 & \\
\hline
\end{tabular}

Sumber :Data olahan

Tabel IV 3.5

Distribusi Responden berdasarkan Pekerjaan

\begin{tabular}{|c|c|c|c|c|c|}
\hline \multicolumn{6}{|c|}{ Pekerjaan } \\
\hline & & Frequency & Percent & $\begin{array}{c}\text { Valid } \\
\text { Percent }\end{array}$ & $\begin{array}{c}\text { Cumulative } \\
\text { Percent }\end{array}$ \\
\hline \multirow[t]{3}{*}{ Valid } & Pegawai Negeri & 63 & 60.0 & 60.0 & 60.0 \\
\hline & Honorer & 42 & 40.0 & 40.0 & 100.0 \\
\hline & Total & 105 & 100.0 & 100.0 & \\
\hline
\end{tabular}

Sumber :Data olahan

Tabel 3.6

Distribusi Responden berdasarkan Pendidikan Terakhir

\begin{tabular}{cccccc}
\hline \multicolumn{5}{c}{ Pendidikan Terakhir } \\
\hline & Frequency & Percent & $\begin{array}{c}\text { Valid } \\
\text { Percent }\end{array}$ & $\begin{array}{c}\text { Cumulative } \\
\text { Percent }\end{array}$ \\
\hline Valid & SD/SMA/Sederajat & 47 & 44.8 & 44.8 & 44.8 \\
& D3 & 11 & 10.5 & 10.5 & 55.2 \\
& S1 & 43 & 41.0 & 41.0 & 96.2 \\
S2 & 4 & 3.8 & 3.8 & 100.0 \\
& Total & 105 & 100.0 & 100.0 & \\
\hline
\end{tabular}

Sumber :Data olahan 
Pengaruh Sistem Informasi Penerimaan Pajak Reklame terhadap Peningkatan ........

Uji validitas digunakan untuk mengetahui kevalidan kuesioner dalam mengumpulkan data. Untuk menguji pertanyaan satu dengan yang lainnya valid atau tidak, maka pengujiannya dilakukan dengan menggunakan product moment Versi 24.00 for Windows. Imam G .(2013).h.52. Kriteria pengujiannya dilakukan dengan cara membandingkan rhitung dengan rtabel pada taraf $\alpha=0,05.4$ Item Kuesioner dalam uji validitas dikatakan valid jika Rtabel < Rhitung pada tingkat signifikan 5\%. dan sebaliknya item angket dikatakan tidak valid jika Rtabel > Rhitung pada tingkat signifikan 5\%. Rtabel di tentukan dengan rumus: $\mathrm{df}=\mathrm{N}-2 . \mathrm{df}=105-2=103$.Sehingga di ketahui Rtabel $=0.250$.

Tabel 3.7

Uji Validitas Sistem informasi Penerimaan Pajak Reklame

\begin{tabular}{ccccc}
\hline Variabel & Item & Rhitung & Rtabel & Keterangan \\
\hline Sistem & 1 & $\mathbf{0 , 8 4 4}$ & 0,250 & Valid \\
informasi & 2 & $\mathbf{0 , 5 5 2}$ & 0,250 & Valid \\
penerimaan & 3 & $\mathbf{0 , 8 3 2}$ & 0,250 & Valid \\
pajak reklame & 4 & $\mathbf{0 , 8 0 5}$ & 0,250 & Valid \\
(X) & 5 & $\mathbf{0 , 5 4 0}$ & 0,250 & Valid \\
& 6 & $\mathbf{0 , 5 7 9}$ & 0,250 & Valid \\
& 7 & $\mathbf{0 , 6 2 0}$ & 0,250 & Valid \\
\hline
\end{tabular}

Sumber :Data olahan

Tabel 3.8

Uji Validitas Pendapatan Asli Daerah

\begin{tabular}{crccc} 
Variabel & Item & Rhitung & Rtabel & Keterangan \\
\hline Peningkatan & 1 & $\mathbf{0 , 4 8 5}$ & 0,250 & Valid \\
Pendapatan & 2 & $\mathbf{0 , 6 8 4}$ & 0,250 & Valid \\
Asli Daerah & 3 & $\mathbf{0 , 6 7 7}$ & 0,250 & Valid \\
(Y) & 4 & $\mathbf{0 , 6 7 5}$ & 0,250 & Valid \\
& 5 & $\mathbf{0 , 5 8 7}$ & 0,250 & Valid \\
\hline
\end{tabular}

Sumber :Data olahan

Setelah instrumen penelitian diuji validitasnya, maka dilanjutkan dengan uji reliabilitas instrumen untuk mengetahui tingkat kepercayaan instrumen penelitian yang digunakan sebagai alat pengumpulan data. Uji reliabilitas terhadap instrumen penelitian yang dihitung menggunakan rumus cronbach's alpha. Suatu instrumen penelitian dikatakan reliabel apabila nilai instrumen reliabilitas itu sendiri memiliki nilai reliabilitas $\geq 0,60$. Tetapi jika nilai reliabilitas instrumen $\leq 0,60$ maka instrumen tidak reliabel dan tak dapat digunakan dalam penelitian. V.Wiratna Sujarwen(2015).h. 93172. 
Tabel 3.9

Uji Reliabilitas Sistem Informasi Pajak Rekalme

\begin{tabular}{cccc}
\hline Variabel & Cronbach's Alpha & Kriteria & Keterangan \\
\hline $\begin{array}{c}\text { Sistem Informasi } \\
\text { Penerimaan } \\
\text { Pajak Reklame }\end{array}$ & $\mathbf{0 , 7 9 4}$ & 0,60 & Reliabel \\
\hline
\end{tabular}

Sumber :Data olahan

Berdasarkan tabel di atas, menunjukkan hasil pengujian reliabilitas dengan nilai cronbash's Alpha adalah $0,794>0,60$ sehingga dapat dikatakan bahwa seluruh instrumen yang digunakan tersebut reliabel untuk digunakan.

Tabel 3.10

Uji Reliabilitas Pendapatan Asli Daerah

\begin{tabular}{cccc}
\hline Variabel & Cronbach's Alpha & Kriteria & Keterangan \\
\hline $\begin{array}{c}\text { Peningkatan } \\
\text { Pendapatan Asli } \\
\text { Daerah }\end{array}$ & $\mathbf{0 , 6 3 3}$ & 0,60 & Reliabel \\
\hline
\end{tabular}

Sumber : Data olahan

Berdasarkan tabel di atas, menunjukkan hasil pengujian reliabilitas dengan nilai cronbash's Alpha adalah $0,633>0,60$ sehingga dapat dikatakan bahwa seluruh instrumen yang digunakan tersebut reliabel untuk digunakan.

Uji normalitas pada model regresi digunakan untuk menguji apakah nilai residual yang dihasilkan dari regresi terdistribusi secara normal atau tidak. Uji normalitas data dalam penelitian ini menggunakan Uji One Sample KolmogorovSmirnov (Uji K-S). Dasar pengambilan keputusan pada uji normalitas ini adalah: jika signifikan/probabilitas $>0,05$ maka data berdistribusi normal, jika nilai signifikan/probabilitas $<0,05$ maka data berdistribusi tidak normal.

Tabel IV 3.11

Uji Normalitas Kolmogrov

Smirnov

\begin{tabular}{l}
\hline One-Sample Kolmogorov-Smirnov Test \\
\hline Unstandardiz ed Residual
\end{tabular}

$\mathrm{N}$

105

Normal Parameters ${ }^{\mathrm{a}, \mathrm{b}}$

Mean

.0000000

Std.

1.42086300

Deviation

Most Extreme

Absolute $\quad .076$

Differences

Positive $\quad .065$

Negative $\quad-.076$

Al-Muqayyad

Vol 4 No 2 (2021) 
Pengaruh Sistem Informasi Penerimaan Pajak Reklame terhadap Peningkatan

Test Statistic

Asymp. Sig. (2-tailed)

a. Test distribution is Normal.

b. Calculated from data.

c. Lilliefors Significance Correction.
.076

$$
.149^{\mathrm{c}}
$$

\section{Sumber: Data olahan}

Berdasarkan uji normalitas kolmogrov smirnov pada tabel diatas diketahui bahwa nilai Asymp.Sig.sebesar 0,149>0,05. Dapat disimpulkan bahwa nilai residual diatas berdistribusi normal, sehingga dapat dilanjutkan ke peneilitan selanjutnya.

Uji t digunakan untuk mengetahui apakah variabel independen berpengaruh secara signifikan atau tidak terhadap variabel dependen. (Sugiyono, 2014:261). Untuk melihat pengaruh variabel dependen terhadap variabel independen, uji t dilakukan dengan membandingkan nilai thitung dengan ttabel dengan kriterianya yaitu: jika thitung < ttabel maka hipotesis ditolak berarti tidak ada pengaruh, jika thitung > ttabel maka hipotesis diterima berart terdapat pengaruh.Diketahui nilai ttabel pada taraf signifikasi 5\% (2-tailed) dengan persamaan berikut: $\mathrm{df}=\mathrm{n}-2$; alpha $=5 \%, \mathrm{df}=105-2$; $0.05 / 2, \mathrm{df}=105 ; 8,168$,Ttabel $=1,983$.Berdasarkan output tabel 11 di atas, diketahui nilai thitung $(8,168)>$ ttabel $(1,975)$ artinya hipotesis diterima.

Uji koefisien determinasi (R Square) dalam regresi linear sederhana digunakan untuk mengetahui persentase sumbangan pengaruh variabel independen $(\mathrm{X})$ terhadap variabel dependen (Y). Persentase tersebut menunjukkan seberapa besar variabel independen dapat menjelaskan variabel dependen. Semakin besar koefisien determinasinya, maka semakin baik variabel independen dalam menjelaskan variabel dependennya. (Setiaji, Bambang, 2004:20).

\section{Tabel IV}

3.12

\section{Uji Koefisien Deteminasi R}

Square

\begin{tabular}{ccrcr}
\hline \multicolumn{5}{c}{ Model Summary } \\
\hline Model & R & R Square & $\begin{array}{c}\text { Adjusted R } \\
\text { Square }\end{array}$ & $\begin{array}{r}\text { Std. Error of } \\
\text { the Estimate }\end{array}$ \\
\hline 1 & $.627^{\mathrm{a}}$ & .393 & .387 & 1.42774
\end{tabular}

a. Predictors: (Constant), Sistem Informasi Penerimaan

Pajak Reklame

Berdasarkan tabel uji koefisien determinasi R Square IV.14 menjelaskan nilai ( $\mathrm{R}$ square) sebesar 0,393. Hal ini menunjukkan bahwa persentase pengaruh kontribusi Sistem Informasi Penerimaan Pajak Reklame (X) terhadap Peningkatan Pendapatan Asli Daerah (Y) diketahui berpengaruh sebesar 39,3\%. Sedangkan sisanya sebesar $60,7 \%$ dipengaruhi atau dijelaskan oleh variabel lain yang tidak dimasukkan

\section{Al-Muqayyad}

Vol 4 No 2 (2021) 
dalam model penelitian ini. Maskud dari variabel lain yang tidak dimasukan dalam model penelitian ini yaitu selain dari variabel $\mathrm{X}$ dan $\mathrm{Y}$, apabila terjadi penambah variabel lain atau variabel baru contoh variabel pengawasan.

Regresi linear sederhana bertujuan untuk mempelajari hubungan linear antara dua variabel. Dua variabel ini dibedakan menjadi variabel bebas $(\mathrm{X})$ dan variabel tak bebas (Y). Variabel bebas adalah variabel yang bisa dikontrol, sedangkan variabel tak bebas adalah variabel yang mencerminkan respon dari variabel bebas. (Dergibson Siagian dan Sugiarto, 2000:224).

\begin{tabular}{|c|c|c|c|c|c|}
\hline \multicolumn{6}{|c|}{$\begin{array}{c}\text { TabelIV3.3 } \\
\text { Uji Regresi Linear } \\
\text { Sederhana } \\
\end{array}$} \\
\hline \multicolumn{6}{|c|}{ Coefficients $^{\mathbf{a}}$} \\
\hline & \multicolumn{2}{|c|}{ Unstandardized } & Standardized & & \\
\hline & \multicolumn{2}{|c|}{ Coefficients } & \multicolumn{2}{|l|}{ Coefficients } & \\
\hline \multicolumn{5}{|l|}{ Model } & Sig. \\
\hline $1 \quad$ (Constant) & 6.109 & 1.395 & & 4.379 & .000 \\
\hline Sistem Informasi & .456 & .056 & .627 & 8.168 & .000 \\
\hline \multicolumn{6}{|l|}{ Penerimaan Pajak } \\
\hline a. Dependent Variable & gkatan $\mathrm{P}$ & ndapatan A & sli Daerah & & \\
\hline
\end{tabular}

Dari tabel di atas, diketahui nilai constant (a) sebesar 6,109, koefisien regresi ariabel Sistem Informasi Penerimaan Pajak Reklame (X) sebesar 0,456 menyatakan bahwa setiap penambahan 1\% dari nilai Sistem Informasi Penerimaan Pajak Reklame. Maka nilai Peningaktan Pendapatan Asli Daerah sebesar 0,456. Dapat diketahui nilai koefisien regresi tersebut benilai positif.

\section{SIMPULAN}

Dari hasil penelitian didapat disimpulkan bahwa terdapat pengaruh Hasil uji t (parsial) diketahui nilai thitung 8,168 > ttabel 1,983. Sedangkan berdasarkan nilai signifikan uji t (Parsial) dapat dilihat pada kolom tabel sig bahwa nilai signifikan sebesar $0,000<0,05$. Sehingga dapat dinyatakan Ha diterima maka hasil jawaban rumusan masalah ke-2 dan hipotesis, dapat disimpulkan bahwa adanya pengaruh antara variabel Sistem Informasi Penerimaan Pajak Reklame (X) terhadap variabel Peningkatan Pendapatan Asli Daerah (Y). Sedangkan pengaruh X terhadap Y sebesar $39,3 \%$. Sedangkan sisanya sebesar $60,7 \%$ dipengaruhi atau dijelaskan oleh variabel lain yang tidak dimasukkan dalam model penelitian ini. 
Pengaruh Sistem Informasi Penerimaan Pajak Reklame terhadap Peningkatan

Berdasarkan hasil penelitian yang telah dilakukan dalam rangka mengetahui pengaruh sistem informasi penerimaan pajak reklame terhadap peningkatan pendapatan asli daerah pada Badan Pendapatan Daerah Kabupaten Bengkalis.Maka saran dari penulis adalah penggunakan terhadap aplikasi khusus pajak reklame untuk memudahkan kinerja pegawai dalam pengiputan data wajib pajak reklame dan penyelnggara reklame dan menghimbau kepada wajib pajak dan penyelenggara reklame agar membayar pajak tepat waktu untuk meningkatkan pendapatan asli daerah, karena pajak reklame termasuk dalam sumber dari pendapatan asli daerah.

\section{REFERENSI}

Abdul Halim. (2008). Akuntasi Sektor Publik Akuntasi Keungan Daerah. Jakarta: Salemba Empat,

Azhari, A. Samudra. (2005). Perpajakan Di Indonesia Keuangan, Pajak Dan Retribusi. Jakarta: PT. Hecca Mitra Utama.

Baridwan Zaki. (2012). Sistem Akuntansi Penyusutan Prosedur dan Metode. Yogyakarta: BPFE

Bungin Burhan, (2010). Metodologi Penelitian Kuantitatif; Komunikasi, Ekonomi dan Publik Serta Ilmu - Ilmu Sosial Lainnya. Jakarta: Kencana

C. West Chrucman. (1968). The System Approach. New York: Dell.

Dariana, \& Wella Desriyanti. (2017). Analisis Sistem Informasi Akuntansi Pembayaran Biaya Tagihan Pemakaian Air Bersih Pada Perusahaan Daerah Air Minum (PDAM) Cabang Bengkalis. Jurnal Akuntansi Syariah, 1(2)

Della Nurnafiyanti. (2015). Pengaruh Penerimaan Pajak Reklame Terhadap Pendapatan Asli Daerah (PAD) Kota CImahi (Studi Kasus Pada Dinas Pendapatan Daerah Kota Cimahi). Fakultas Ekonomi Universitas Widayatama, Skripsi. Bandung.

Departemen Agama RI. (2010). Al-Qur'an dan Terjemahannya. Jakarta: Karya Toha

Dergibson Siagian, \& Sugiarto. (2000). Metode Statistika: Untuk Bisnis dan Ekonomi. Jakarta: PT. Gramedia Pustaka Utama.

Dokumentasi RENSTRA pada Badan Pendapatan Daerah Kabupaten Bengkalis

Eka Lestari. (2008). Pengaruh Sistem Informasi Perpajakan dan Lama Masa Kerja Sebagai Pemeriksa Pajak Terhadap Kemampuan Pemeriksaan Pajak. Jurnal Akuntansi, 1(5).

Fitrianto. \& Mukayyat. (2012). Sistem Akuntansi Zakat pada Badan Amil Zakat Kecamatan Bantan Bengkalis. Jurnal Iqtishaduna, 1(2).

Gusfahmi. (2007). Pajak Menurut Syariah. Jakarta PT. RajaGrafindo Persada. 
Jepri Paulanda. (2017). Sistem Informasi Pengelolaan Pajak Reklame Dengan Metode Official Assesment, Studi Informasi Universitas Sari Mutiara Indonesia. Jurnal Mahajana Informasi, 2 (2) .

Khuzan Rahman. (2007). Pengaruh Pemungutan Pajak Reklame Terhadap Pendapatan Asli Daerah (PAD) Ditinjau Dalam Perspektif Ekonomi Islam" Fakultas Ekonomi Bisnis Islam. Jurusan Ekonomi Islam. Universitas Islam Negeri (UIN) Raden Intan Lampung| Skirpsi Online,

Munawir. (2000). Perpajakan. Yogyakarta: Liberty.

Muri Yusuf A . (2014). Metode Penelitian Kuantitatif, Kualitatif, dan Penelitian Gabungan. Jakarta: Penerbit Prenadamedia Grup.

Noor Juliansyah. (2011). Metodelogi Penelitian. Jakarta: Kencana Pernada Media Group, Edisi Pertama.

Pratisto Arif. ( 2004). Cara Mudah Mengatasi Masalah Statistik dan Rancangan Percobaan dengan SPSS 12. Jakarta: PT. Elex Media Kompotindo.

Rahman. (2005). Kamus Besar Bahasa Indonesia. Jakarta: Trimedia.

Rizki Indrawan. (2015). Pengaruh Kontribusi Pajak Reklame Terhadap Pendapatan Asli Daerah (Studi Kasus Terhadap Dinas Pendapatan Kota Bandung)". ASSET Jurnal Polban. Proceeding

Setiaji, Bambang. (2004). Panduan Riset dengan Pendekatan Kuantitatif. Surakarta: Program Pascasarjana UMS.

Siahaan Marihot Pahala. (2003). Pajak Daerah \& Retribusi Daerah Berdasarkan Undang-Undang Nomor 28 Tahun 2009 Tentang Pajak Daerah dan Retribusi Daerah. Jakarta: Rajawali Pers.

Siahaan Marihot Pahala. (2006). Pajak Daerah \& Retribusi Daerah. (Jakarta: RajaGrafindo Persada,

Simanjuntak Timbul Hamonangan, et.all. (2012). Dimensi Ekonomi Perpajakan dalamPembangunan Ekonomi. Jakarta: Penerbit Swadaya Grup.

Siregar Syofian. (2013). Metodologi Penelitian Kuantitatif. Jakarta: Kencana CetakanPertama.

Siregar Syofian. (2010). Statistika Deskriptif untuk Penelitian: Dilengkapi Perhitungan Manual dan Aplikasi SPSS Versi 17. Jakarta: PT Raja Grafindo Persada.

Sri Rudiati. (2013). Sistem Informasi Penghitungan Pajak Reklame Di Dinas Pendapatan, Pengelolaan Keuangan Dan Aset Daerah Kabupaten Karanganyar Berbasis Multiuser. Jurnal Tikmosin, 1(1).

Suandy Erly (2005). Hukum Pajak. Jakarta: Penerbit Salemba Empat. 
Pengaruh Sistem Informasi Penerimaan Pajak Reklame terhadap Peningkatan ........

Sugianto. (2007). Pajak dan Retribusi Daerah. Jakarta: Grasindo.

Sugiyono. (2014). Statistik Untuk Penelitian. Bandung: Alfabeta, Cet. Ke-24

Sujarwen V.Wiratna. (2015). Statistik Untuk Bisnis \& Ekonomi. Yogyakarta, Pustaka Baru Press.

Sukrisno Agoes. (2012). Akuntansi Perpajakan. Jakarta: Salemba Empat.

Undang-Udang Republik Indonesia Nomor 28 Tahun 2007 Tentang Perubahan Ketiga atas Undang-undang Nomor 6 Tahun 1983 Tentang Ketentuan Umum dan Tata Cara Perpajakan

Undang-Undang Nomor 33 Tahun 2004 Tentang Perimbangan Keuangan Antara Pusat dan Pemerintahan Daerah Pasal 1 butir 18

Usaman Husaini. \& Purnomo Stiady Akbar. (2011). Pengantar Statistika, Edisi Kedua, Jakarta: PT. Bumi Aksara

Warsito. (2001). Hukum Pajak. Jakarta: PT. Rajawali Grafindo Persada.

Yelti Septiria. (2016). Pengaruh Penerapan Sistem Informasi Direktorat Jendral Pajak dan Kepuasan Kerja Terhadap Kinerja Pegawai (Studi Kasus Pada Kantor Pelayanan Pajak Pratama Bandung Tegallega). Jurnal Ekonomi Volume, 1(5) 